\title{
Narración oral de cuentos y poemas para niños del Asentamiento Humano Helechales. Informe diagnóstico y proyección*
}

\author{
Beatriz Vanegas Athías \\ Especialista en Semiótica y Pedagogía de la Lengua Materna \\ Magíster en Semiótica, docente investigadora del grupo Interdisciplinario \\ de Investigación Educativa ESPIRAL, Centro de Estudios en Educación \\ Universidad Santa Tomás Seccional Bucaramanga, Colombia. \\ Correo electrónico: ceedifusion@mail.ustabuca.edu.co
}

Recibido: 28 de junio de 2015 - aprobado:12 de agosto de 2015

\section{Cómo citar este artículo}

Vanegas, B. (2015). Narración oral de cuentos y poemas para niños del Asentamiento Humano Helechales. Informe diagnóstico y proyección. Espiral. Revista de Docencia e Investigación, 5(2), 75-96.

\section{Resumen}

El objetivo de este artículo de investigación es presentar el diagnóstico y su consecuente análisis que ha servido como punto de partida al proyecto "Narración oral de cuentos y poemas para niños del Asentamiento Humano Helechales. Inclusión social y formación de seres de lenguaje". Se trata de un proyecto en curso, que además de fomentar la lectura en una comunidad vulnerable cuya extrema pobreza (31 niños del Asentamiento Humano Helechales, ubicado en la Transversal Oriental de Floridablanca, Santander, Colombia) Ios confina al hacinamiento en viviendas tuguriales, les ayuda a incluirse socialmente. Ello porque cada vez que un niño o una niña escucha una historia o la lee, descubre que los libros son objetos que tienen múltiples sentidos, y que en cada sesión, cuando se abra el "Había una vez..." y se cierre el libro con "...el Colorín Colorado...", cada niño trabaja de forma explícita e implícita en la construcción de sentido de su espíritu y de su ser como ciudadano. La metodología empleada es la propia del paradigma cualitativo, es decir, la investigación acción.

Los resultados parciales del proyecto surgen de un proceso de análisis sistémico orientado por la presencia de herramientas como la encuesta y la entrevista y los fundamentos teóricos empleados. Así, se obtuvieron cinco categorías que resultaron del trabajo de campo y que arrojaron como resultado la configuración de la comunidad de Asohelechales: 1. Gustos lectores/hábitos; 2. Recreación; 3. Información demográfica (conformación familiar, ingresos, nivel de escolaridad de los padres, ac- ceso a medios de comunicación); 4. Creencias e imaginarios; 5. Ciudadanía (inclusión - exclusión), participación, derechos, reconocimiento.

Palabras clave: Narración oral, diagnóstico, categoría, inclusión social, literatura, promoción de lectura.

\begin{abstract}
The goal of this research paper is to present the diagnosis and its analysis that has served as a starting point for the project Oral storytelling and poems for children in the Human Settlement Helechales. Social inclusion and training language beings. This is an ongoing project that is also to encourage reading in a vulnerable community whose extreme poverty (thirty -one children) in the Human Settlement Helechales, located in the Eastern Transversal, Floridablanca, Santander (Colombia). They are confined to overcrowding in slams. This project helps them to be socially included. This is because every time a boy or a girl hears or reads a story, he discovers that books are objects that have multiple meanings, and that in every session, when he opens the "Once upon a time ..." and closes the book with "... the Colorín Colorado ...", the expressions work, explicitly and implicitly, in building a sense of his spirit and his being as a citizen. The methodology used is action research, qualitative research paradigm.

Partial results of the project emerge from a systemic analytical process guided by tools such as the survey, the interview and theoretical principles. Thus, five categories
\end{abstract}

* Artículo de investigación producto del proyecto homónimo en curso, adscrito a la VI convocatoria interna del Centro de Investigaciones Universidad Santo Tomás. 
were identified from the fieldwork in the community Asohelechales: 1. Readers' tastes/ habits; 2 . Entertainment 3. Demographic information (family conformation, income, parents' educational level, access to media) 4. Beliefs and imaginary; 5. Citizenship (Inclusion -exclusion) Participation, rights recognition.

Keywords: Oral history, diagnosis, category, social inclusion, literature, reading promotion.

\section{Introducción}

Los asentamientos humanos son conglomerados que se originan de manera simultánea a los procesos de urbanización y concentración de las actividades económicas, sociales, culturales e industriales de una comunidad. Son en gran medida, el producto de las migraciones campo-ciudad y de los aumentos anuales de población que vivencian los países que están en vías de desarrollo, como Colombia. El Asentamiento Humano Helechales, situado en la carretera Transversal, vía Bucaramanga - Floridablanca, Santander, Colombia, no es un conjunto homogéneo, sino múltiple y complejo.

Existe un amplio grupo de familias que decidieron conformar el Asentamiento Humano Helechales, no precisamente por razones atribuibles a la más reciente versión del conflicto armado en Colombia. La miseria, la desindustrialización de las tres últimas décadas manifiesta en el desempleo, la nula capacitación para acceder a los empleos y la consecuente iliquidez económica familiar que impide acceder a un salario para pagar los altos costos de los arriendos en barrios como La Cumbre, hizo que muchas familias que hoy integran el Asentamiento Humano Helechales emigraran dentro de la misma ciudad. Ellos constituyen entonces una nueva tipología del desplazado: el desplazado por la desindustrialización y el fracaso en la política económica colombiana de las tres últimas décadas de acuerdo con Hernández (s.f.).

(...) después de la mitad del siglo veinte el desarrollo fue muy centralizado, y el país comenzó a sufrir una gran dependencia de la industria del café. De esta forma, la falta de capacitación e investigación en otros sectores productivos, junto con cambios drásticos en los precios internacionales del grano, hicieron que la industrialización cafetera no contagiara positivamente los demás niveles productivos del país.

De ahí que la arquitectura hallada responde a un grupo de viviendas humildes arrumadas en una colina. Las condiciones del lugar sobre el cual están edificados los hogares, evidencian los riesgos y adversidades que pueden padecer los habitantes de Helechales, debido a la vertiginosidad del terreno conformado por montículos y lomas. En la construcción de las viviendas todo vale: los habitantes fungen como arquitectos y reciclan todo material propicio para la construcción: vallas y material publicitario en general. Allí se eternizan los anuncios de los candidatos a cargos públicos.

Las viviendas son de madera, palos, tablas, láminas de zinc y piedras que en su mayoría están recubiertas de un plástico verde que ayuda a encontrar el asentamiento a todo aquel que desee llegar a él. En este asentamiento humano nombrado Aso Helechales, situado en la carretera transversal a la salida del municipio de Floridablanca hacia Bucaramanga (Santander, Colombia) se ha hecho, durante tres años, el trabajo e interacción con los niños, pues son ellos los posibles gestores de una nueva cultura ciudadana. Por la experiencia con la comunidad, los niños son más abiertos y tienen menos prejuicios frente a sujetos de otro contexto social, son ellos los más indicados para promover un cambio en la medida que haga parte de una ciudadanía universal, como sujetos del lenguaje, de forma participativa e incluyente.

¿Cómo se modifican las competencias comunicativas y sociales de los niños y las niñas del Asentamiento Humano Helechales, a partir de su inmersión en un proceso de lectura literaria en voz alta?

La anterior pregunta constituye la investigación que intentamos responder y desarrollar 


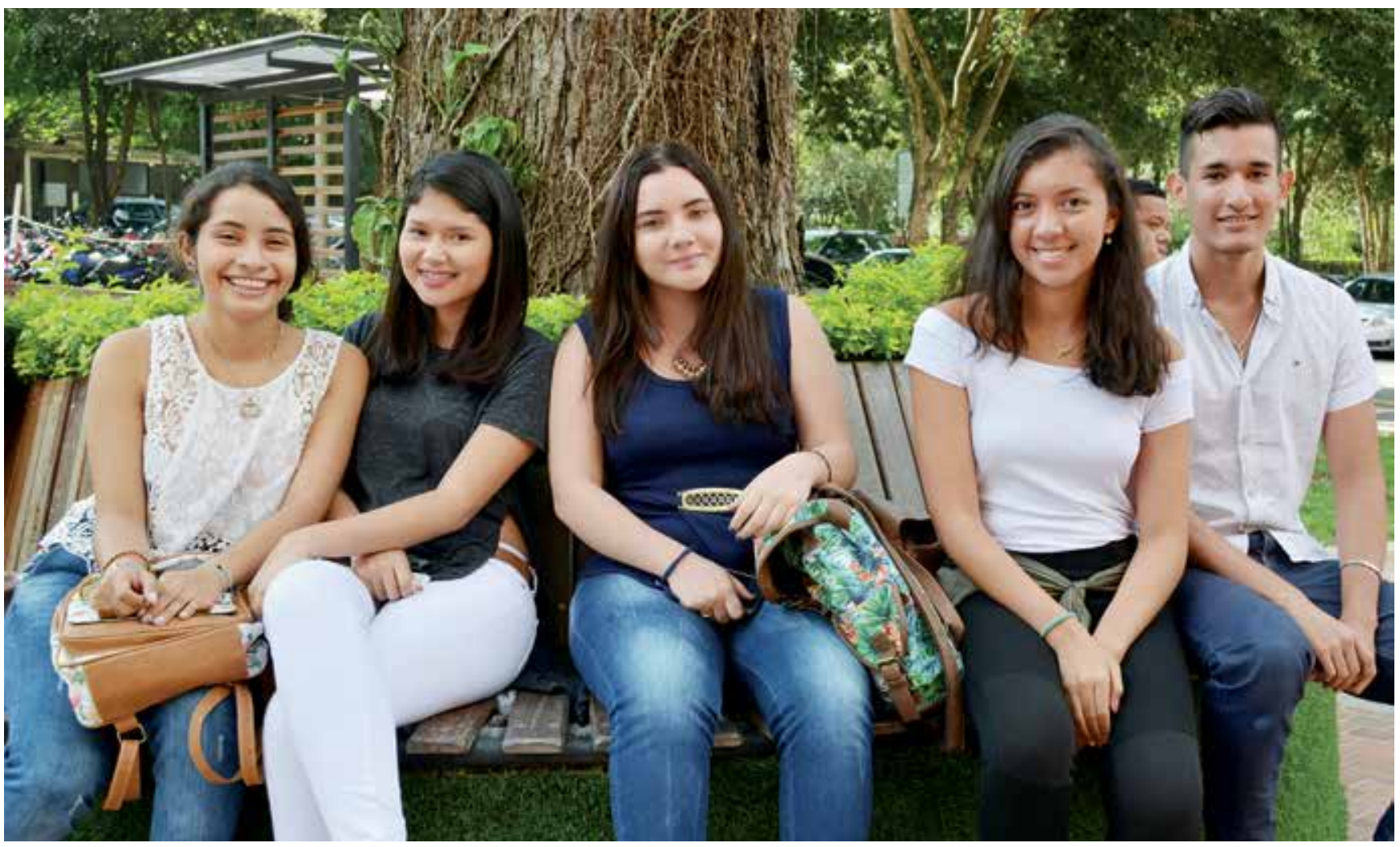

en el transcurso de esta investigación. Para ello nos trazamos los siguientes objetivos:

- Valorar el nivel de desarrollo de las competencias comunicativas de los niños y las niñas del Asentamiento Humano Helechales, a partir de la configuración de un diagnóstico de la comunidad en categorías sociales y cognitivas que la representen.

- Promover la construcción de hábitos lectores para contribuir en la formación de ciudadanos sujetos de lenguaje, a través del discurso literario leído en voz alta a niños de la primera y segunda infancia del Asentamiento Humano Helechales de Floridablanca, Santander.

- Identificar los cambios que surgen a partir de la mediación pedagógica de la narración oral, en las relaciones interpersonales de los niños y las niñas en la familia y en la escuela.

- Emplear el acto de lectura en voz alta para incorporar a niños y niñas a la historia de la humanidad, a través de los mundos posibles que configura el discurso literario.

- Fomentar sujetos de lenguaje que accedan a los libros concebidos como puentes para la inclusión social en el desarrollo de sus competencias comunicativas y el reconocimiento de la diversidad.

- Gestionar la dotación de una biblioteca de literatura infantil y juvenil clásica y contemporánea para el Asentamiento Humano Helechales, con el fin de garantizar una secuencia ininterrumpida del proceso lectoescritor propuesto en el presente proyecto.

\section{Metodología}

Nuestro objeto de mediación pedagógica, definido en la pregunta central de investigación, fue abordado desde la investigaciónacción. Al respecto (Elliot, 1999) señala que el objetivo de este tipo de investigación es proporcionar elementos que sirvan para facilitar el juicio práctico en situaciones concretas y la va- 
lidez [...] depende [...] de su utilidad para ayudar a las personas a actuar de modo más inteligente y acertado (1993, p. 88) Se trata de una mediación social y una investigación que lleva a la acción social. El abordaje del problema de investigación no se refiere exclusivamente a un conocimiento dentro de una disciplina del saber, sino a una situación específica en un contexto social real: se trata de cuarenta niños de un asentamiento humano que fueron tocados por la cercanía planificada con el discurso estético literario, al que accedieron mediante la narración oral y la lectura silenciosa y en voz alta, para identificar los cambios que se producen en sus habilidades, actitudes, valores y conocimientos, tanto comunicativos como sociales.

Es probable que ciertos convencimientos y certezas de la investigadora sean matizados por alguna desviación en el curso de los acontecimientos o mediaciones. El enfoque cualitativo permite estas "licencias" si son lo suficientemente relevantes y definitorias. Es decir, según Elliot (1999) en muchos casos, es muy difícil determinar con antelación si el investigador podrá o no modificar la situación de partida para la investigación-acción.

Las técnicas que se aplicaron fueron la observación y el consecuente registro del comportamiento humano visualizado en Helechales, tanto en los espacios colectivos o comunitarios como en los familiares; la entrevista a padres de familia, niños y maestros, la actividad de preguntar, que fue en profundidad el enfoque cualitativo, hace énfasis en indagar la minucia, lo particular, lo singular; y la entrevista grupal, que por su naturaleza no estructurada resulta útil en la socialización y evaluación de la mediación, a grupos que oscilen entre cinco y diez miembros (niños, niñas, madres y padres de familia) para evitar efectos perniciosos, conflictos o inhibiciones y bloqueos de los participantes.

En este sentido el enfoque seleccionado para la investigación presente es coherente con la naturaleza de los textos literarios que aspiramos nos sirvan como mediadores en la construcción de sujetos de lenguaje. Porque la verdadera literatura, la que da cuenta de la condición humana es un bello y estético informe de nimiedades, pequeños detalles, insignificantes y particulares hechos que son en verdad la sal, la esencia, lo trascendente del devenir del hombre. Dicho en otras palabras, apuntamos a la universalidad de lo particular.

De lo anterior se desprende que son dos los ámbitos en los que se analizó esta relación entre la inmersión en procesos de lectura literaria en voz alta y silenciosa y el desarrollo de competencias comunicativas y sociales: la familia y la escuela. La observación de lo cotidiano en la vida de las familias de los treinta niños del asentamiento humano Helechales, que conformarán la población sujeta a estudio, aunada al análisis de lo que sucede en el contexto escolar de estos niños y niñas, a partir del inicio de la mediación pedagógica.

La investigación, entonces, se desarrolló en tres fases (Montero, 1998) susceptibles de continuo ajuste o sanción: Contacto con la comunidad; Elaboración del plan de acción e Implantación del curso de acción. En el presente artículo se dará cuenta de la primera fase:

Contacto con la comunidad: o acercamiento al Asentamiento Humano Helechales para caracterizar la población. Es necesario reconocer la conformación familiar, nivel de escolaridad de los padres, edades de los niños, determinar hábitos lectores y hábitos de recreación, establecer si tienen acceso a medios de comunicación (televisión, radio, prensa, revistas), si tienen acceso a bibliotecas del sector o de alguna institución, entre otros aspectos esenciales.

Para el planteamiento del problema de investigación se hizo necesario realizar cuatro inmersiones en el Asentamiento Humano Helechales, que permitieron recoger datos y revisarlos. Se aplicó una encuesta, se efectuó un diálo- 


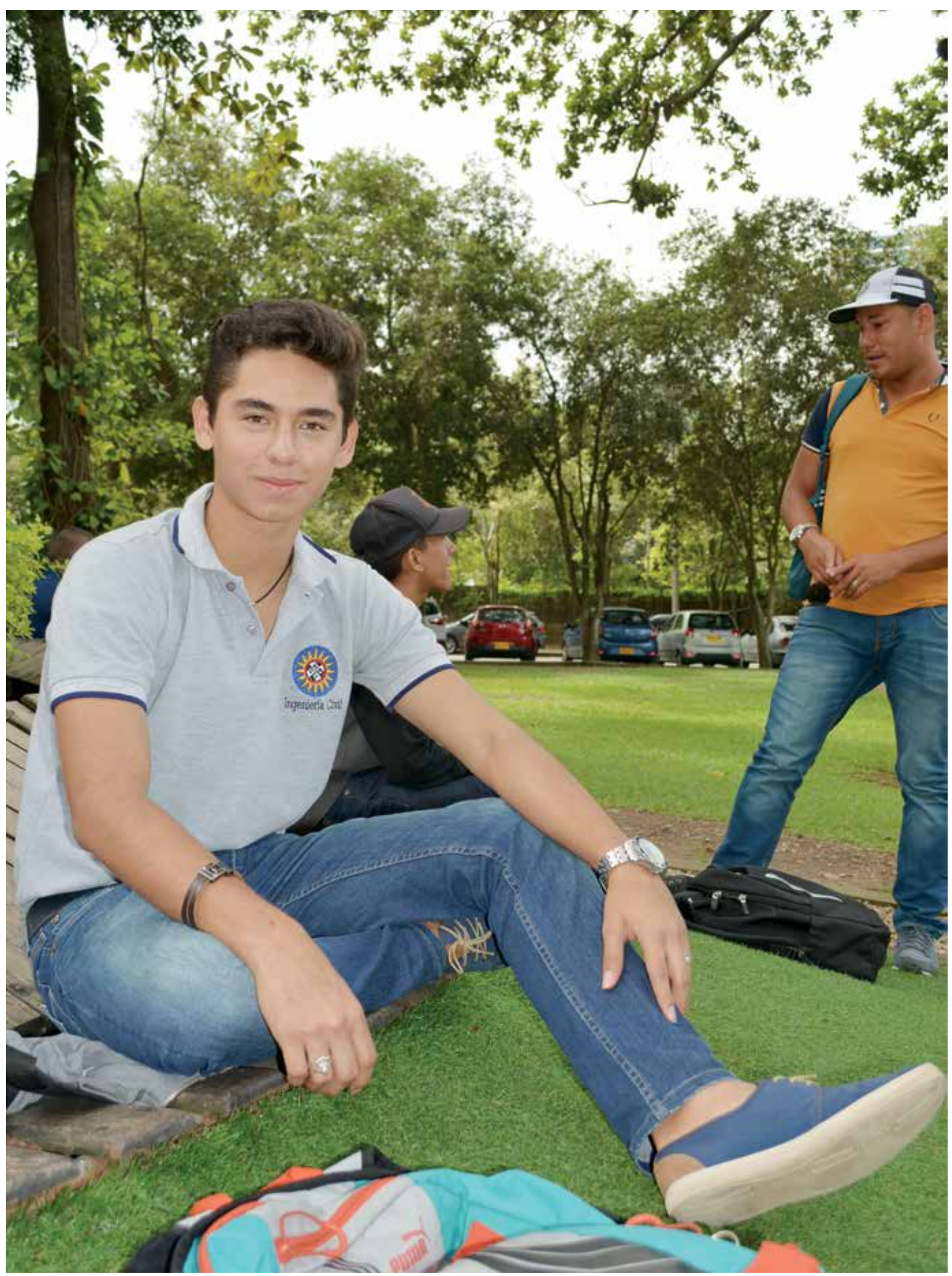


go directo con una población muestra conformada por cuarenta familias, y se desarrollaron cinco sesiones de narración oral de cuentos y poemas a treinta niños. Esto corresponde a la primera fase del proceso investigativo que consiste en hacer contacto con la comunidad para describir minuciosamente los hechos o situaciones trascendentes para el afianzamiento de la formulación de la pregunta de investigación. En esta descripción se utilizaron como técnicas de recolección de datos la mencionada encuesta y el diálogo informal con la comunidad.

El presente artículo da cuenta, como se afirma en el resumen, de la configuración de la comunidad a través de un diagnóstico que marcará el derrotero de la investigación.

Elaboración del plan de acción: con base en la caracterización de la población se diseñarán los instrumentos de recolección de información sobre el nivel de competencias comunicativas y sociales de los niños y las niñas de Helechales.
Implantación del curso de acción: con base en el plan de acción, se iniciará el desarrollo de las actividades de mediación pedagógica a partir de las diversas actividades de narración oral, con el fin de formar hábitos lectores.

Las gráficas que a continuación presentamos se erigen como evidencias de cinco categorías que hemos hallado en el trabajo de campo realizado en el Asentamiento Humano Helechales en la fase uno llamada Contacto con la comunidad.

1. Gustos lectores/hábitos

2. Recreación

3. Información demográfica
a. Conformación familia
b. Ingresos
c. Nivel de escolaridad padres
d. Acceso a medios de comunicación

4. Creencias e imaginarios

5. Ciudadanía (inclusión - exclusión), participación, derechos, reconocimiento.

\section{Gustos y hábitos lectores}

Herramienta empleada: Entrevista semiestructurada.

Sujetos: padres y madres de los niños del asentamiento humano Helechales.

Hábitos lectores.

\section{1. ¿Dedican tiempo para leer con sus hijos?}
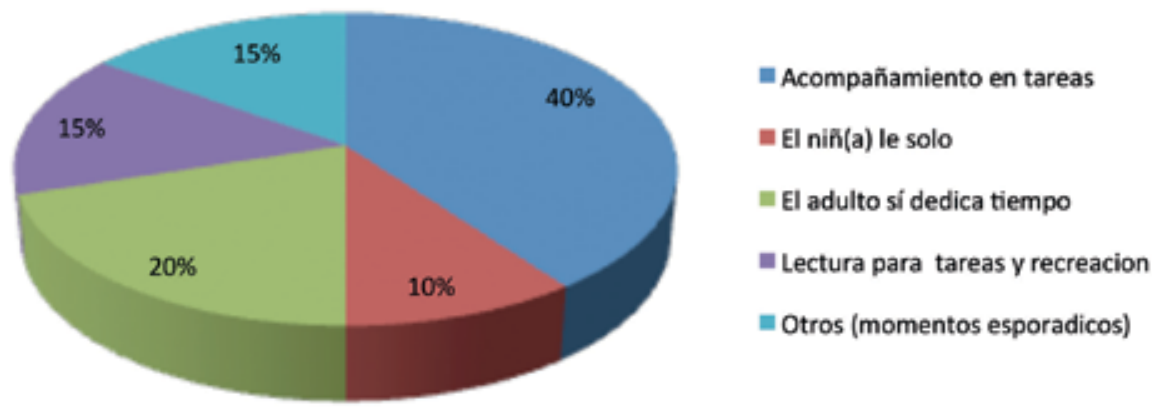

El $40 \%$ de los padres únicamente se limita al ejercicio de acompañar a sus hijos a hacer las tareas, muchas de ellas no son lecturas de libros o textos sino ejercicios de consulta, actividades didácticas u operaciones matemáticas. Es decir, la orientación de los padres hacia la lectura de literatura infantil es muy dispersa y el $20 \%$ que dedica el tiempo prefiere, por cuestión de 
recursos, leer periódicos locales, revistas de entretenimiento o la Biblia. Además, cabe resaltar que los padres de estos niños ocupan la mayoría del tiempo en su trabajo y al momento de dedicar o abrir el espacio de la lectura lo hacen de manera apresurada y su disposición no es la adecuada para el ejercicio de la lectura.

La ausencia del adulto responsable como guía o promotor de lectura arroja a nuestro proyecto el reto de construir una Escuela de Padres, como bien se ha planteado en el Plan de Acción del proyecto. Es menester sensibilizar a los padres sobre la importancia y utilidad del acompañamiento lector siquiera media hora diaria, porque de acuerdo con Guillilan citado por Arroyave (2008) "Podrás tener numerosas riquezas tangibles: cofres con joyas y baúles de oro. Pero más rico de lo que soy no podrás ser; tuve una madre que me leyó".

\section{2. ¿Qué se lee en tu casa?}
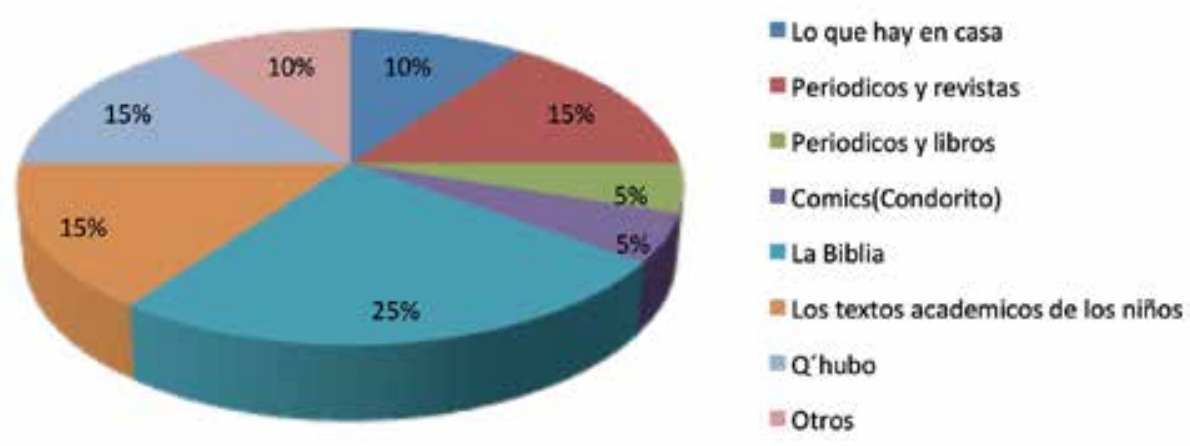

El $25 \%$ de las familias encuestadas lee la $\mathrm{Bi}-$ blia demostrando que es una comunidad creyente. Otra de las actividades relevantes es leer el periódico con un $20 \%$, donde el más cercano es el $Q$ 'hubo, un periódico popular de Bucaramanga y su área metropolitana, que se consigue en una de las tiendas de la comunidad o con sus propios vecinos.

Se puede apreciar la deficiencia de libros de literatura, libros que abran la imaginación de los niños, que los lleven a mundos distintos y los hagan soñar.

Este resultado constituye un referente directo para la selección de los textos que conformarán la biblioteca del Asentamiento Humano Helechales, dado que los lectores directos serán los niños, pero los padres de familia también conforman potenciales usuarios de los talleres y de la Biblioteca.

\section{Frecuencia en las visitas a la escuela del hijo(a)}

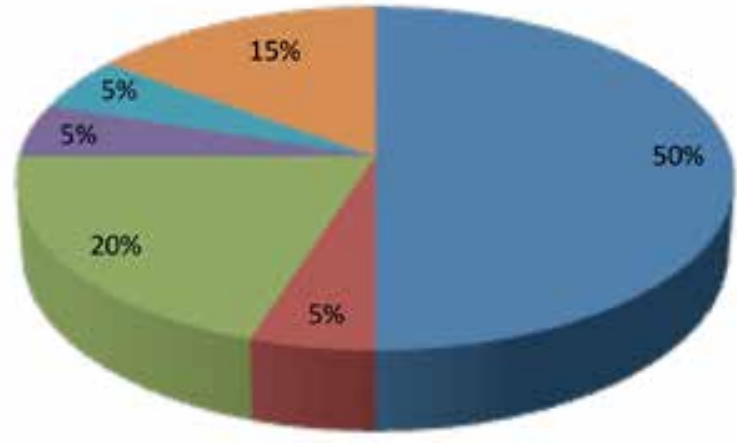

$$
\begin{aligned}
& \text { " Cuando hay reuniones } \\
& \text { = Eventos institucionales } \\
& \text { = Al recoger o llevar al niño(a) } \\
& \text { = Seguido } \\
& \text { = Citación del colegio } \\
& \text { = Otros }
\end{aligned}
$$


El $50 \%$ de los padres están muy pendientes de la situación académica de sus hijos(as), pues las reuniones son para entrega de boletines o hablar con los profesores de cómo va el niño(a), tanto académicamente como en su comportamiento o convivencia en el colegio.

Y un $20 \%$ de los padres visitan el colegio todos los días de manera más espontanea, para recoger a los niños(as), ya que de regreso a sus casas deben caminar por la transversal Oriental vía al Carmen, lo cual es peligroso porque tiene pocos andenes peatonales.

Los padres de los niños(as) consideran la educación muy importante para la vida de sus hijos(as), porque este es uno de los factores para que se formen como ciudadanos y a futuro "progresen y estén bien", como lo indicó una de las mamás. Las escuelas a las que van los niños son públicas y aledañas al lugar donde viven, y el hecho de que no estén escolarizados preocupa a los responsables de los niños.

\section{4. ¿Qué te gustaría que tu hijo leyera?}

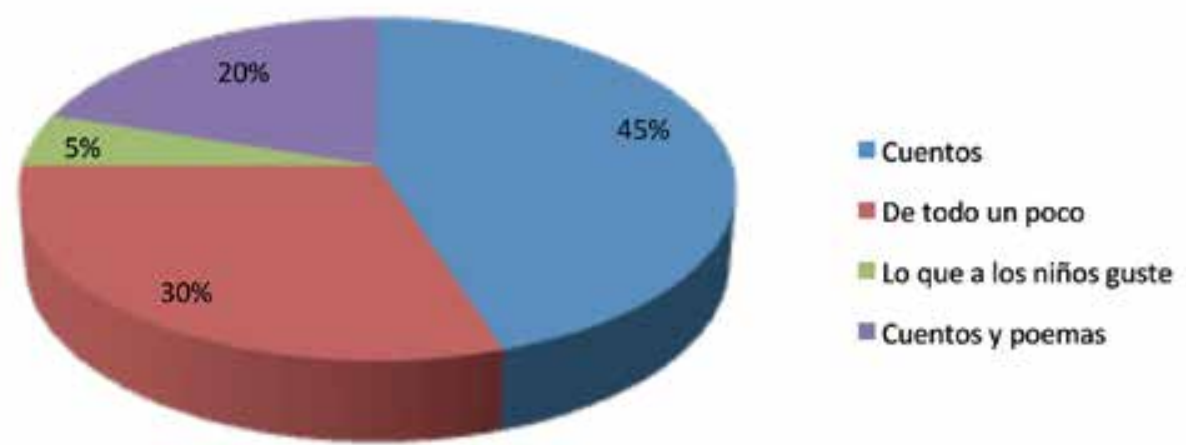

A veces la expresión "de todo un poco", con un $30 \%$, demuestra el desconocimiento que tienen los padres frente a la literatura o las diferentes maneras de expresar el mundo de las palabras. Aunque un $45 \%$ de la muestra tomada respondían "cuentos" porque re- sultan ser los más adecuados para la edad de los niños(as). Se debe empezar un proceso de pedagogía con esto, pues la literatura infantil no solo son cuentos, sino que incluye ilustraciones, refranes, rondas, poemas, retahílas y muchas más.

\section{Acompañamiemto familiar}

Herramienta empleada: Encuesta semiestructurada.

Sujetos: padres y madres de los niños del asentamiento humano Helechales.

\section{1. ¿Cuántos miembros tiene la familia?}

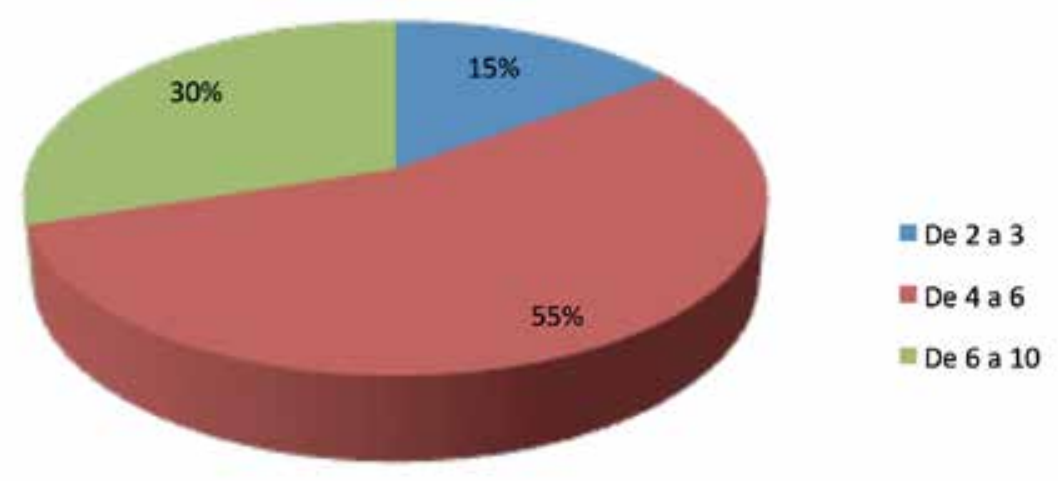


Las familias que constituyen el asentamiento humano de Helechales están conformadas en un $55 \%$ entre seis y diez integrantes. Luego, en un $30 \%$ con cuatro a seis miembros $y$, finalmente, el $15 \%$ de dos a tres integrantes.

Sorprende observar cómo durante las primeras visitas al asentamiento notamos que sa- lían niños de todos los sitios al mismo tiempo que nos dirigíamos al Salón Comunal. Vale decir que el Salón Comunal es el sitio de reunión de la Junta de Acción Comunal, el punto de encuentro para el almuerzo comunitario, y el sitio donde se realizan los talleres de narración oral de cuentos y poemas.

\section{2. ¿Quién está al frente de la familia?}

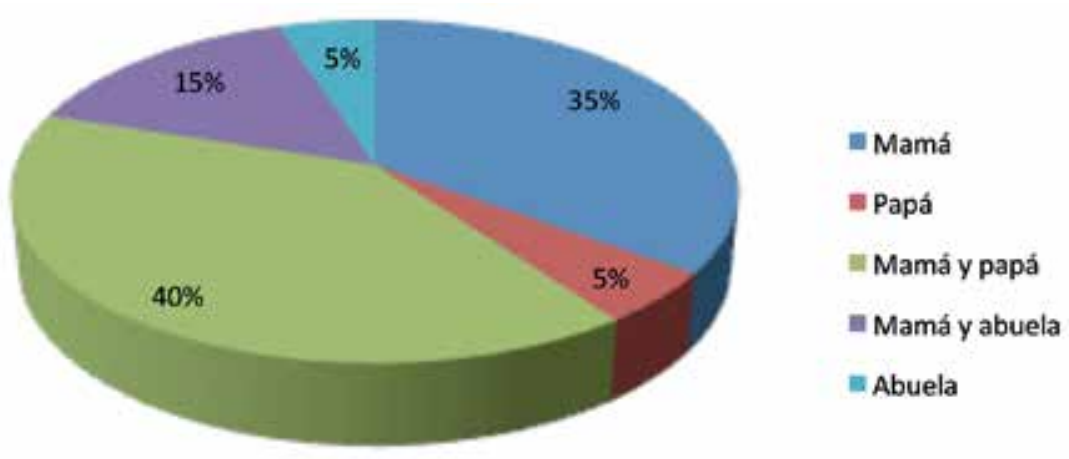

En el $40 \%$ de las familias son ambos padres quienes se encargan del sostenimiento de la casa y del suministro de las provisiones primarias. En seguida, se encuentra que en un 35\% de las casas son solo las madres las responsables del sustento y cuidado de sus hogares. Le sigue, con un 15\%, madre en compañía de abuela, y se concluye que un 5\%, es la abuela o el padre quien asume la tarea del sustento.

Llama la atención que todas las entrevistas realizadas fueron respondidas por mujeres o madres que estaban al frente del hogar o porque el padre se encontraba trabajando.

\section{Oficios que hace el padre de familia}

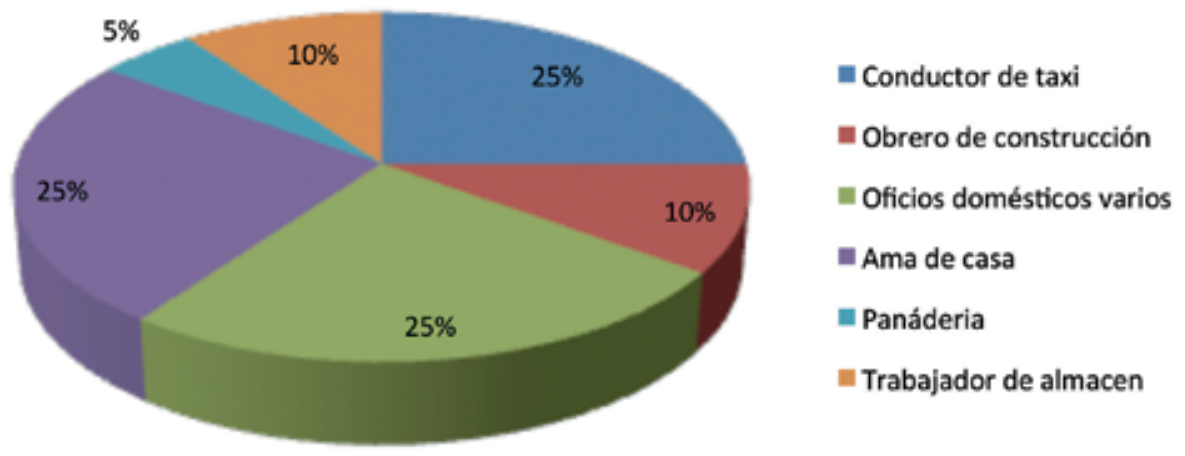

En las labores que desempeñan los padres, se reparten con un $25 \%$ cada una, el de ama de casa, trabajos domésticos y conducción de taxi. Luego, los oficios en un almacén y las labores de construcción con el 10\%, respectivamente. Y el trabajo en una panadería con el 5\%.
Este resultado responde al contexto arriba mencionado de la desindustrialización que ha vivido el país y que ha dejado fuera de la oferta laboral a estos ciudadanos que, entre otras razones, no trascienden la básica secundaria en su formación educativa. La siguiente gráfica corrobora esta variable: 


\section{4. ¿Qué estudios cursó?}

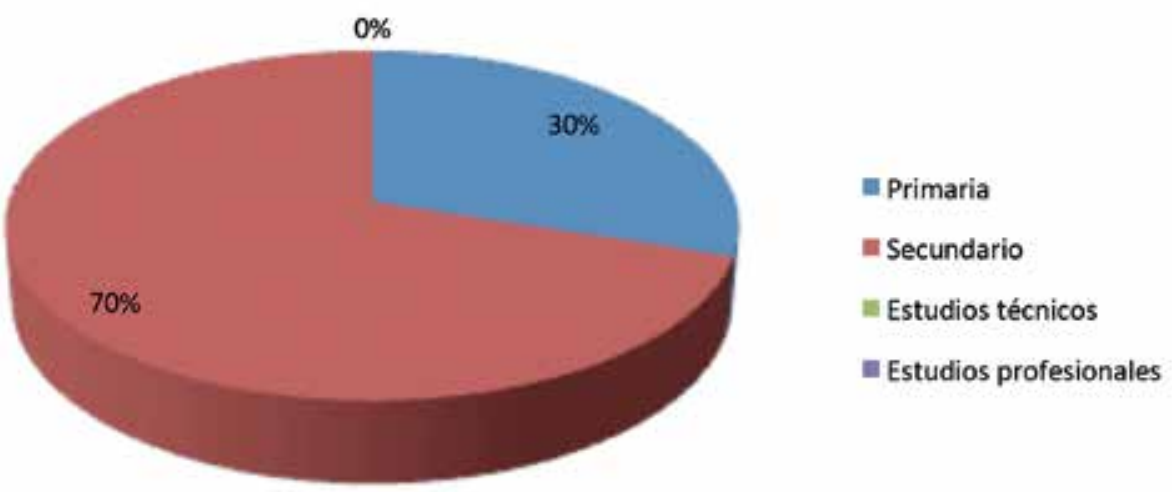

El nivel de estudios realizados es en un $70 \%$ secundario o bachillerato. Le sigue el nivel básico o primario con un $30 \%$. Y no hay registros de niveles técnicos o profesionales. Sin embar- go, existe un número de cinco padres de familia interesados en validar su bachillerato con la proyección de continuar estudios técnicos que permitan una integración al sistema laboral.

\section{El salario mensual}

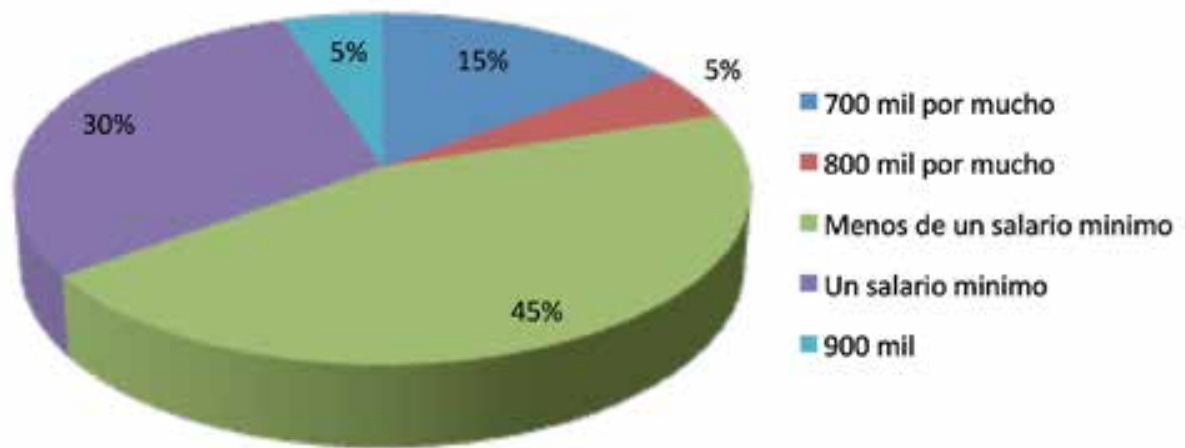

Un $45 \%$ de familias percibe un salario inferior al mínimo legal vigente. Después, un 30\% cuenta con un salario mínimo legal vigente. Le sigue un $15 \%$ con una cifra cercana a los 700

\section{Gustos lectores}

Herramienta mixta: Entrevista semiestructurada.

Sujeto: niños y niñas. mil pesos $y$, por último, un $5 \%$ con un valor de 800 mil y 900 mil pesos, como sueldo mensual. En general el dinero empleado para sostener el día alimenticio no supera los $\$ 5000$.

\section{1. ¿Sabes leer?}

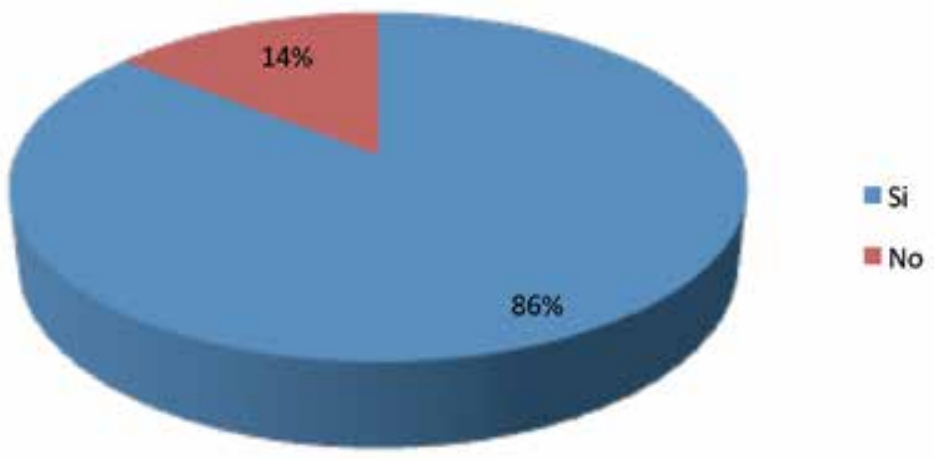


De la población de niños encuestados el $86 \%$ saben leer a razón de su edad y grado escolar. Así mismo, hay casos de niños autodidactas que han aprendido a leer a través de sus hermanos mayores o por un trabajo de observación de comportamientos o desarrollo de tareas de familiares o amigos. Por otra parte, el $14 \%$ restante lo conforman niños de la primera infancia, que debido a su nivel de escolaridad no han tenido lecciones lectoescritoras y que solo realizan una lectura de las imágenes o gráficos de los libros con los que se ha trabajado.

\section{2. ¿Te gusta leer o que te lean?}

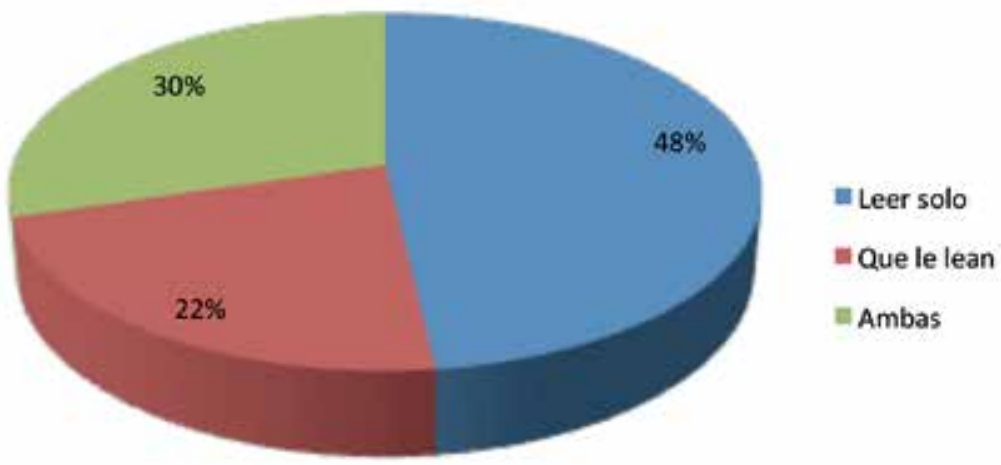

El $48 \%$ de los niños encuestados prefiere realizar una lectura solitaria, llevada o dirigida por ellos; muchos de los que ya saben leer prefieren ser la voz que dirija la lectura, ya sea para ellos mismos como un ejercicio personal o para leerle a los compañeros, para generar una sensación de liderazgo en ellos (comportamiento que asocian al realizado por nosotros). Un 22\% de ellos sienten una mayor atracción por la lectura cuando es guiada o contada por otra persona, ya que se sienten más atrapados con la historia y el lector juega con matices de voz en su relato, siendo este un factor que los motiva con los cuentos, entre esta población también están los que no saben leer y que para dar sentido a los libros y los cuentos necesitan de un guía. Así mismo, el $30 \%$ de los niños se sienten atraídos por la lectura de diversas formas, ya sea relatada la historia por alguien más o realizada la lectura por ellos mismos; muchos de ellos resaltaban que su interés principal era conocer y disfrutar las historias independiente de la forma de hacerlo.

\section{3. ¿Qué libros prefieres?}

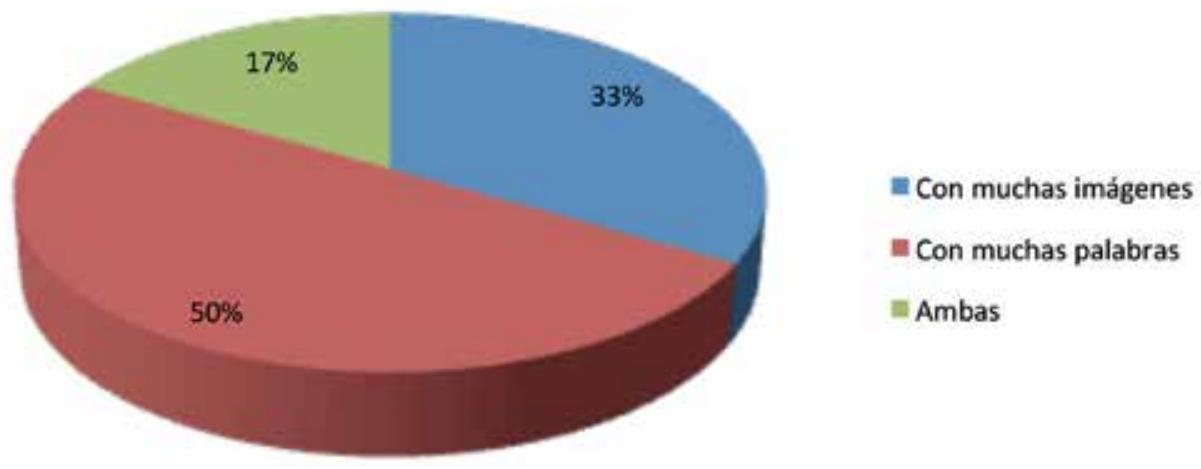

La mitad de la población entrevistada prefiere que sus libros contengan muchas palabras, el orden de ideas que pueda contarles una más larga aventura o una historia más sustanciosa. Por otra parte, el 33\% de ellos sienten mayor interés en libros que sean animados y contengan 
muchas imágenes que contrasten o soporten lo que va relatando el cuento; muchos de los niños que prefieren libros con mayor cantidad de imágenes son aquellos que están comenzando con su aprendizaje lectoescritor y no cuentan con una gran habilidad en su lectura. Así mismo, el $17 \%$ de ellos se sienten atraídos por los libros, independientemente de si su contenido es con muchas imágenes o palabras, pues cualquiera de estas dos opciones les genera interés.

\section{4. ¿Cuál es tu animal favorito?}

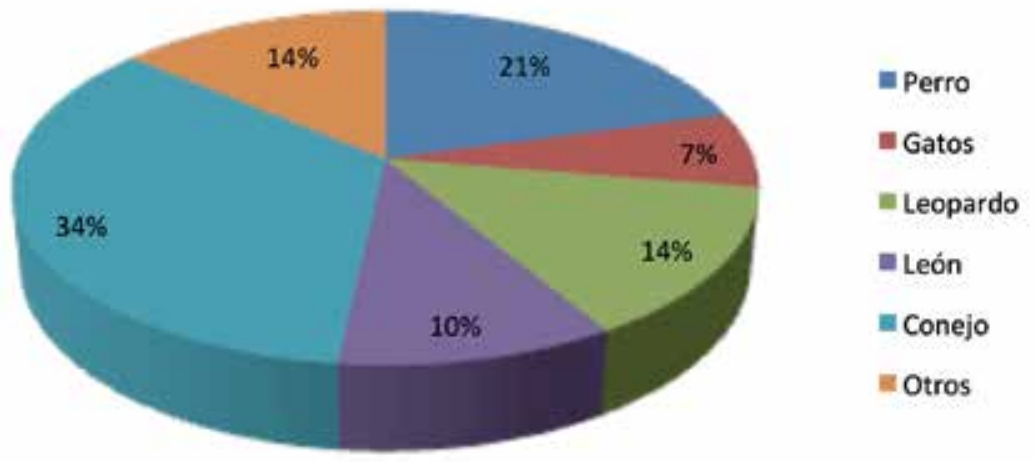

Referente a esta pregunta hubo diversas respuestas, pues aunque los niños se sienten atraídos o interesados por los animales, la preferencia por uno u otro está principalmente en lo que representa el animal para ellos; en este sentido, el animal que les genera más gusto es el conejo, ya que para las niñas, principalmente, representa suavidad y dulzura. Del mismo modo, otro de los animales de más frecuencia entre los favoritos es el perro, debido a que muchos de los niños tienen perros como mascota y tienen una cercanía física y sentimental por esta especie. Algunos de los niños sienten admiración o inquietud por animales grandes e imponentes como el león o el leopardo, a pesar de conocer de ellos muy poco. $Y$ aunque a su alrededor hay muchos gatos, no es el animal favorito, ya que aunque están cerca, no es una especie que se distinga por su cercanía o juego, que es una actitud que resulta de vital importancia para los niños.

A partir de estos resultados se configuró la inicial lista bibliográfica que constituirá la Biblioteca del Asentamiento Humano Helechales, para la que, según la fiscal, tesorera y secretaria de la Junta de Acción Comunal, ya existe un espacio constituido por cuatro paredes de ladrillo sin techo, sin puerta, ni ventanas y plagado de maleza. Pero este se proyecta como la Biblioteca planeada en uno de los objetivos específicos de nuestro proyecto.

\section{5. ¿Qué tipo de historia te gusta?}
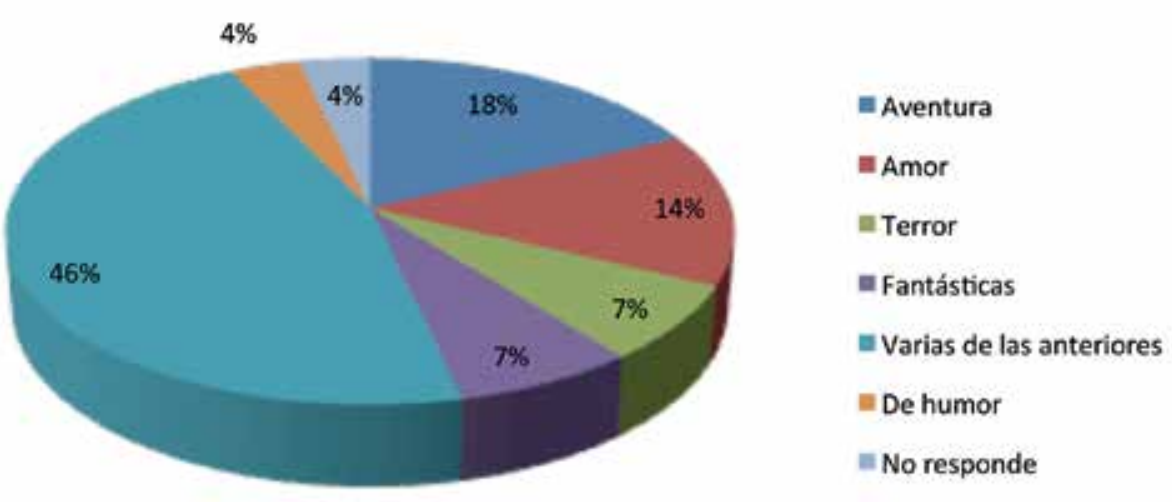
De acuerdo con la gráfica, se puede mostrar una respuesta generalizada dependiendo de la intención de leer cualquier tipo de cuentos y textos. Es, por tanto, una constante el deseo existente por parte de la infancia, de acercarse al mundo literario y narrativo, con el objetivo de afianzar las capacidades de aprendizaje y mejorar la comprensión de lecturas de cualquier temática que se plantea en la pregunta. En un análisis más específico, es posible inferir la predilección de las historias de aventura, con un promedio de respuesta única del $18 \%$. Dicha evidencia, hace posible diagnosticar el deseo del infante de acercarse a emociones constantes, retos mentales y físicos que se planteen para los personajes a través de la historia. En otro tópico, las historias de amor poseen un porcentaje de respuesta del 14\%, lo cual demuestra el interés de los niños y niñas de conocer un mundo de afecto, de amor y de cariño, que se pueda traducir en algún momento a sus realidades propias. La inquietud por las relaciones de amistad, de pareja y de amor en general, refleja en los niños una sensación de curiosidad, de explorar un mundo desconocido que la literatura recrea mediante la interacción de personajes afines, solidarios, respetuosos, tolerantes y comprensivos. En otro aspecto, el terror y la fantasía, pese a ser los temas más solicitados inicialmente por los niños en las visitas de campo, en el plano de las preguntas directas y personales, sus inquietudes disminuyen constantemente, hasta un 7\%, para cada opción de respuesta.

\section{6. ¿Qué se lee más en tu casa?}

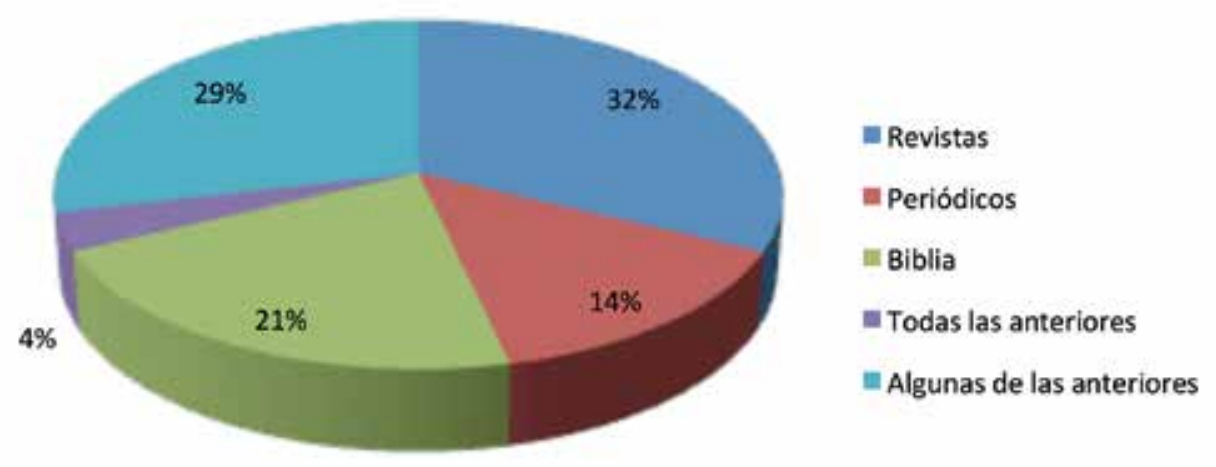

La respuesta a esta pregunta manifiesta la generalización que hacen los niños a la hora de responder una inquietud que posee múltiples respuestas. A pesar de lo anterior, se tiene en cuenta que la prioridad lectora en los hogares de los infantes, son las revistas de variedades, entretenimiento, y actualidad, en un $32 \%$ de la población. La presencia de dichos medios de comunicación masivos en los hogares es debido a una mayor facilidad en el acceso a ellos, y así mismo el costo que tienen. Por otra parte, las creencias religiosas son preponderantes en un número considerable de hogares. Debido a esto, la Biblia, con un $21 \%$ de las familias, se hace indispensable para la lectura que los padres comparten con sus hijos, lo cual pretende de la mención y reproducción de las ideas bíblicas y creencias que de ella se desprenden. La dificultad para obtener periódicos en la zona deja una brecha enorme en la posibilidad de lectura de noticias referentes a la actualidad de la política, la sociedad y los conflictos de la ciudadanía en general y, por tanto, quedan relegados en la lectura cotidiana, por medios audiovisuales, como la televisión. Debido a esto se presenta un $14 \%$ de hogares que los adquieren y leen, lo cual deja una gran diferencia entre las demás opciones de respuesta. 


\section{7. ¿Qué medios tecnológicos se emplean más en tu casa?}
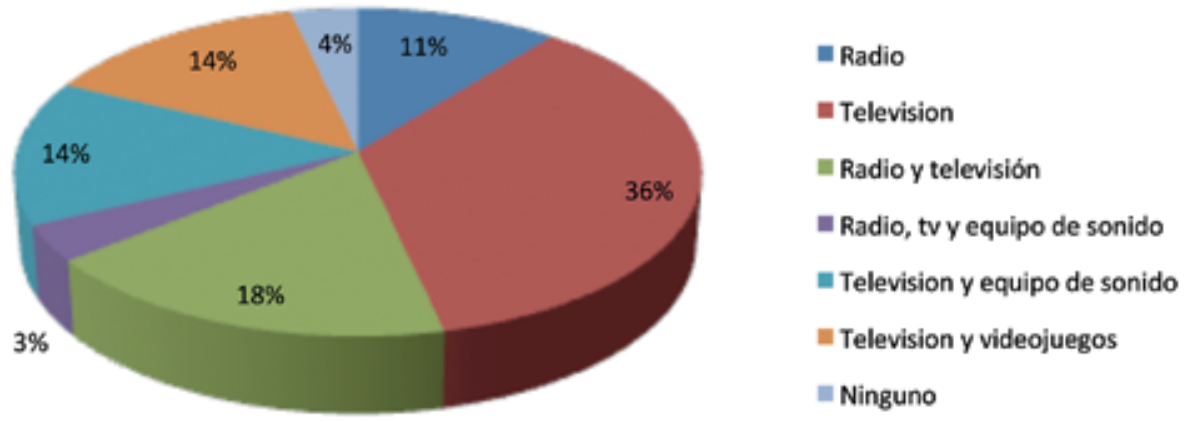

La televisión como medio de comunicación, tecnológico y de entretenimiento se hace indispensable para la comunidad a nivel general. De esta manera, el porcentaje de respuesta es de un $36 \%$, lo cual sustenta el planteamiento inicial. El servicio de televisión, aunque es limitado, se establece como el aparato electrónico más usado en los hogares. Además, el radio y el equipo de sonido acompañan en otros momentos del día la relación con los medios tecnológicos. Los canales y emisoras que se ven y

escuchan respectivamente son en su mayoría de índole nacional. En otro aspecto, los niños en particular, usan el televisor de manera simultánea con los videojuegos, a los que se hace referencia con profunda emoción y detalle. Lo anterior revela que el tiempo libre de los infantes está ocupado en su mayoría por actividades que no incluyen el desarrollo de hábitos lectores, y que por tanto, no se evidencia un avance lecto-escritor, más allá de la formación básica primaria que reciben en los colegios.

\section{8. ¿Conoces alguna biblioteca?}

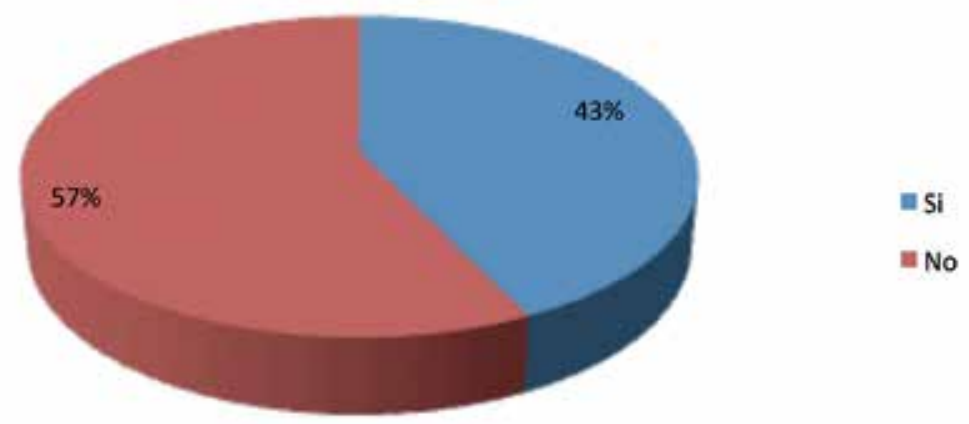

La cercanía, el conocimiento, el tacto, la sensación, los olores son vitales para el reconocimiento de la literatura en los libros de narraciones, cuentos, poemas y demás. En función de tal afirmación, es posible evidenciar la carencia de acentuación de los procesos de hábitos de lectura en los niños entrevistados, debido a la falta de contacto con los libros como tal. Lo anterior se relaciona, de manera más precisa, con el reconocimiento de bibliotecas que le facili- ten a la infancia dicha relación, lector-libro. En un $57 \%$ de la población entrevistada, es posible evidenciar la carencia de reconocimiento del acceso público a libros que traten los diferentes gustos en particular. La falta de bibliotecas de fácil acceso para toda la ciudadanía, sin importar condición social, y la lejanía de dichos espacios del asentamiento en que se encuentran establecidos los hogares, impiden visitarlos, y así mismo, explorarlos. Por otra parte, el $43 \%$ 
de los niños menciona como única biblioteca conocida la que se encuentra en el centro educativo al cual asisten para su formación básica. Según esto, el contacto físico y directo con los elementos literarios, para el desarrollo de hábitos lectores, está cerrado a un momento eminentemente escolar.

\section{9. ¿Cuál es tu materia preferida?}
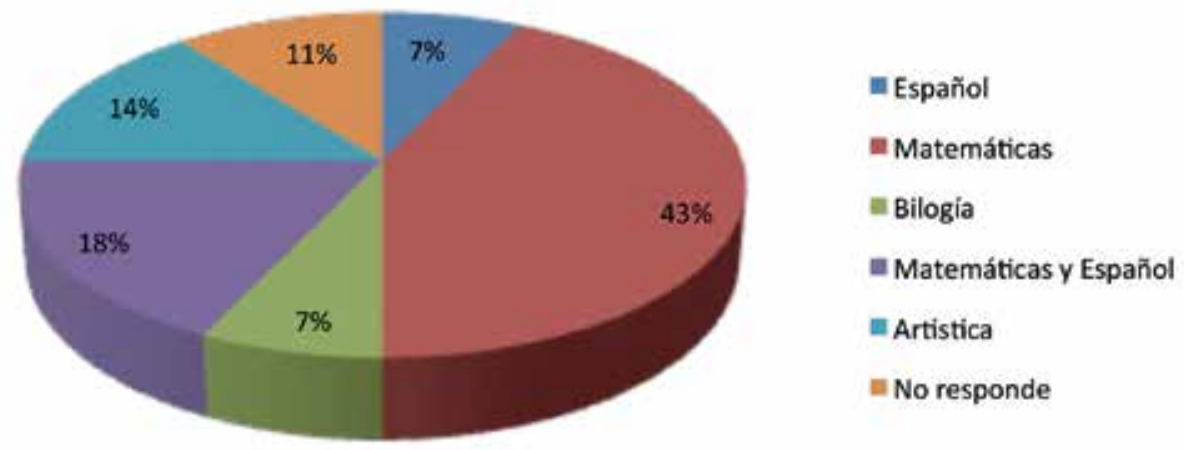

Un número considerable de niños, respondieron Matemática, como su materia preferida. El $43 \%$ de la población evidencia la afinidad de los niños con ciencias exactas y pragmáticas, lo cual, si bien no es inadecuado, genera una preferencia sobre los estudios de las ciencias humanas, como las asignaturas de Español y Artística. Esta predilección está justificada sobre la presunción de utilidad e importancia de las ciencias exactas, como las matemáticas, frente a una menor relevancia de las áreas de humanidades. En este caso, lo anterior evidencia la prevalencia de las actividades académicas prácticas y productivas, sobre las analíticas y reflexivas. Debido a este orden de ideas, la atención de los niños en su adiestramiento familiar y escolar está enfocada a las ciencias prácticas, lo cual genera un proceso limitado en la formación en lectura básica general. Enfrentar esta problemática representa uno de los pilares de la investigación, debido a que la formación de hábitos lectores, fomentará así mismo la pericia en pedagogía literaria y escrita, como también las capacidades de reflexión y argumentación, tópicos básicos de las ciencias humanas. La educación de niños en capacidad de lectura y de comprensión de textos de cualquier tipo, supondrá las bases de la existencia de ciuda- danos reflexivos, analíticos y críticos frente a su realidad, lo cual facilita la solución de las problemáticas sociales, culturales y económicos.

\section{La recreación en el Asentamiento Humano Helechales}

Los hábitos de recreación de los niños del Asentamiento Humano Helechales se centran en actividades obligatorias, en el siguiente orden jerárquico: hacer las tareas asignadas en la escuela, ver televisión, ayudar en los oficios de la casa y jugar. El juego es de capital importancia en la cotidianidad de los niños de Helechales, porque es la única alternativa ante la no existencia de medios tecnológicos a los cuales acceder -excepto en la escuela- y dos tiendas que ofrecen servicio de Internet.

Así, en este predio semirural cobra protagonismo el viento para elevar cometas; la orografía montañosa que permite que entre vivienda y vivienda aparezcan cuevas que se convierten en espacios para armar el juego con muñecas o para escenificar el tradicional juego del escondite; espacios planos en medio de la alta colina donde se puede jugar al fútbol, la lleva, los ponchados, el congelado. Es bien particular observar que el fútbol practicado por estos niños 
no se escenifica con equipos exclusivamente masculinos, aquí los bandos en contienda deportiva son mixtos y no existe ninguna suerte de contemplación con las niñas por parte de los niños: ellas deben asumir una actitud fuerte para no dejarse meter un gol. Es quizás esta dinámica una metáfora de lo que es su vida, vida que transcurre mucho tiempo a la intemperie y sin la tutela de unos padres que están ausentes por los oficios domésticos o en busca del sustento diario.

Jugar para los niños de Helechales también supone combatir el aburrimiento, se juega "para desaburrirse", pero se juega en equipo. Debemos anotar también que los juegos arriba enunciados requieren que haya más de cinco miembros para realizarlos. Igual acontece cuando el juego escogido son las cartas. Así, podemos afirmar que el carácter de grupo prima en el arte del juego y ello sin duda es una variable a favor del desarrollo del proyecto, $\mathrm{Na-}$ rración oral de cuentos y poemas para niños y niñas del Asentamiento Humano Helechales. Hacia la inclusión social mediante la formación de sujetos de lenguaje, si tenemos en cuenta a Edgar Morin cuando afirma:

(...) El juego no sólo es aprendizaje de tal o cual técnica, de tal o cual aptitud, de tal o cual saberhacer. El juego es un aprendizaje de la naturaleza misma de la vida que está en juego con el azar, con el alea (Morin, 2000).

En este contexto, el ambiente de aprendizaje goza de fortalezas para el desarrollo de los objetivos del proyecto, específicamente el que apunta hacia el fomento de sujetos de lenguaje que accedan a los libros concebidos como puentes para la inclusión social en el desarrollo de sus competencias comunicativas y el reconocimiento de la diversidad.

Con relación a los horarios para guarecerse en la cama, el más alto porcentaje de niños va a dormir a las diez de la noche después que han agotado telenovelas y realityes. Los fines de semana persiste el juego como entretención central; sin embargo, surgen dos sitios que son frecuentados por el $50 \%$ de las familias, se trata de los centros recreacionales de Comfenalco y Cajasan, en estos sitios aparece la piscina, espacio muy bien posicionado en las preferencias de los niños. Es una suerte de inclusión social la que ocurre los fines de semana cuando acuden en familia a recrearse.

\section{Resultados}

¿Por qué invertir esfuerzos humanos y económicos alrededor del acto de leer en voz alta a cuarenta niños del Asentamiento Humano Helechales, de Floridablanca? Respondemos esta pregunta retomando a Yolanda Reyes:

No fomentamos la lectura para exhibir bebés superdotados sino para garantizar, en igualdad de condiciones, el derecho de todo ser humano a ser sujeto de lenguaje; a transformarse y transformar el mundo y a ejercer las posibilidades que otorgan el pensamiento, la creatividad y la imaginación (Reyes, 2007, p. 15).

El asentamiento humano Helechales, ubicado en zonas marginales de alto riesgo, está conformado por setenta familias censadas y situadas en la transversal Oriental vía al barrio El Carmen en Bucarica, municipio de Floridablanca (Santander, Colombia). Los 31 niños con quienes se realizará la mediación pedagógica, a través de la lectura en voz alta de cuentos y poemas, poseen edades que oscilan entre los dos y doce años. Es decir, primera y segunda infancia. Provienen de núcleos familiares conformados así: 28 niños viven con la madre y los 6 restantes con ambos progenitores. El número de habitantes promedio por familia se encuentra entre cuatro y seis miembros; el más alto nivel de escolaridad es la básica secundaria. Todos los hogares cuentan con televisor que proyecta la programación de los dos canales privados de la televisión colombiana; RCN y Caracol; carecen de libros para consolidar o programar un momento diario de lectura, pero sí poseen la Biblia para la cual se dispone un espacio de lectura y de recogimiento familiar, además de 
tener acceso al diario popular de Bucaramanga Q'Hubo.

La presencia del libro y del hábito lector no es una costumbre familiar en el asentamiento humano Helechales. Existe en la comunidad otras necesidades básicas que suplir: que la luz eléctrica no falle, pues proviene de una batería artesanal suministrada por la Empresa de Electrificación después de que la comunidad dirigiera a las autoridades de Floridablanca (municipio del área metropolitana del departamento de Santander, Colombia) múltiples solicitudes, tanto por los conductos legales como por los ilegales; que no ocurra avería alguna al pozo que provee de agua a las casas construidas con materiales reciclables o que el invierno no arrase con techos y paredes de las viviendas. Es en este contexto que surge la presente propuesta cuyo objetivo central radica en la formación de hábitos lectores a treinta y un niños que no tienen la opción de acceder a una biblioteca o que nunca han tenido en sus manos y ante sus ojos un libro que no sea para desarrollar una tarea escolar. El proceso de acercar a niños y niñas del Asentamiento Humano Helechales a los libros permitirá acceder al derecho cultural de leer para construirse como persona. Porque, al decir de Jim Trelease cuando un niño no adquiere los conocimientos básicos para actuar como un miembro productivo y responsable de la sociedad, la sociedad en su conjunto -sin hablar del niño individual- pierde (2007).

De lo anterior podemos inferir, siguiendo a Trelease que el costo de educar niños es ampliamente superado por el costo de no educarlos. Educarlos, para nuestro caso, implica emplear el maravilloso mundo de las historias narradas en cuentos y poemas de la más exquisita tradición literaria. Historias y sonoridades leídas en voz alta por un adulto que imprime a su narración matices y entonaciones que hace que su voz sea portadora de ritmos, sentidos y poderosas palabras que ampliarán su léxico. Sin embargo, como afirma la escritora Yolanda Reyes, más importante que la adquisición de un repertorio lingüístico, es aquella revelación sobre los enormes poderes de las palabras. Al descubrir que estas son más eficaces que las acciones para llamar la atención de las personas (2007, p. 63).

La lectura en voz alta en la primera y segunda infancia convierte al oído en la gran puerta de entrada del lenguaje. Mucho antes de que los niños sean capaces de leer los signos escritos de los textos, a través de la lectura en voz alta, es posible beber el sentido de las frases. Sin darse cuenta, los lectores oyentes reciben un legado milenario de conocimiento y comprensión: el idioma que hablan y con el cual se convertirán en sujetos de lenguaje. Pero para llegar a ser dueños de la verdad, de su verdad a través del lenguaje, se necesitan años de continua praxis, un uso continuo de las palabras en una secuencia ininterrumpida.

El lenguaje materializado en el idioma es una herencia inagotable e inabarcable. Los seres humanos por poseer un legado de estas características tenemos la posibilidad infinita de recorrer parajes insondables del espíritu del hombre y de la topografía del mundo. Cuando la sociedad y la educación brindan al niño el derecho a entrar en el idioma de la mano de los libros, guardianes irrefutables, éste aprende a ejercer con plenitud todos los poderes que poseen las palabras, las historias, los argumentos.

\section{Gisbert (2002) observó que}

El uso del lenguaje no solo lleva de la lectura auditiva de las palabras a la lectura silenciosa de los escritos y los textos, y a nuestra propia escritura personal. Nos conduce, por extensión, a leer la diversidad de las manifestaciones de todo lo que existe (p.90)

La literatura es el discurso más amoral y totalizante en tanto en él tienen cabida todo tipo de seres y situaciones. Es un discurso polisémico que configura la metáfora de la tolerancia, por ello, es posible que confluyan en él los Capuleto y los Montesco; un loco cuerdo que invi- 
ta a la desobediencia en pro de la justicia universal en connivencia con un racionalista que entiende la vida como un inmenso banquete que hay que devorar; un bobo convencido que de su balde saldrán pescados en clara alusión a la utopía que siempre acompaña al ser; o una enamorada que teje y desteje aguardando a su amado aventurero, en alucinante alegoría a la capacidad milenaria de esperar que posee la mujer.

Acercar a niños de primera y segunda infancia a la literatura concebida como un discurso estético, es un proceso de gran complejidad cerebral, y en cuanto mayor sea la dimensión estética del texto, más completo y enriquecedor será el proceso de promoción de lectura. Porque, al decir de Joan Manuel Gisbert:

Cuando se ha producido un verdadero acto de lectura, (...) lo que recuerdas no es haber leído unas escenas, unas páginas, sino haber estado en los espacios que con ellas generaste, y haber visto y vivido por ti mismo, con presencia real, lo que allí ocurría, porque fue como si te ocurriera a ti, o a unos personajes muy cercanos (Gisbert, 2007, pp.93)

Por ello, el tema del proyecto que aspiramos a desarrollar, representa un aporte educativo en tanto concepción de la promoción de lectura, no desde los enfoques tradicionales que dimensionan al acto de leer como una variable educativa que baila según los tiempos que corren y el modelo pedagógico en boga, sino, promoción de la lectura literaria para contribuir a la formación de sujetos de lenguaje inscrita en una educación para la cultura de la libertad y libertad "es sentirse hombre y parte, poder soñar, llegar a admitir que estamos hechos de la materia de los sueños" (Farías, 2007, p, 75).

Los niños del Asentamiento Humano Helechales carecen de las más elementales comodidades. Sus vidas crecen a la par de las carencias y esto se refleja en la comunicación defectuosa que despliegan. Jim Trelease apunta que las causas de una comunicación defectuosa se deben a tres circunstancias:

1. Pasar mucho tiempo con compañeros cuyo vocabulario es igual de pobre al de uno.

2. Pasar mucho tiempo oyendo canciones cuyas letras no se entienden, no se oyen bien o tienen mucho lenguaje común y corriente.

3. Pasar poco o ningún tiempo leyendo o escuchando frases completas en contextos significativos y complejos. (Trelease, 2004, p.95)

Este proyecto contribuirá a la formación de sujetos de lenguajes capaces de expresarse claramente y de lograr a través del buen uso del idioma la inclusión social. En un país como Colombia, cuya economía se orienta cada vez más al servicio, la comunicación oral es una herramienta esencial de trabajo:

Entre más valiosas sean las palabras que uno oye, más valiosas serán las que uno produzca al hablar o al escribir. Leerles en voz alta a los estudiantes -de una lengua extranjera o nativaempezando lo más pronto posible en sus vidas y seguir haciéndolo en todos los grados, los expondrá a un modelo de lengua rico, organizado e interesante que por lo menos tendrán como alternativa frente al lenguaje exclusivamente oral de sus compañeros (Trelease, 2004, p. 98).

En este sentido consideramos la lectura como un factor social determinante. $Y$ la lectura, lo ha corroborado numerosas investigaciones, es el corazón de la educación. En plena era de la Tecnología de la Información y la Comunicación, las competencias que deben desarrollar un niño, un joven o un adulto para hacer de éstas una mediación educativa se centran en la formación de "la opinión, el sentido crítico, el pensamiento hipotético y deductivo, las facultades de observación y de investigación, la imaginación, la capacidad de memori- 


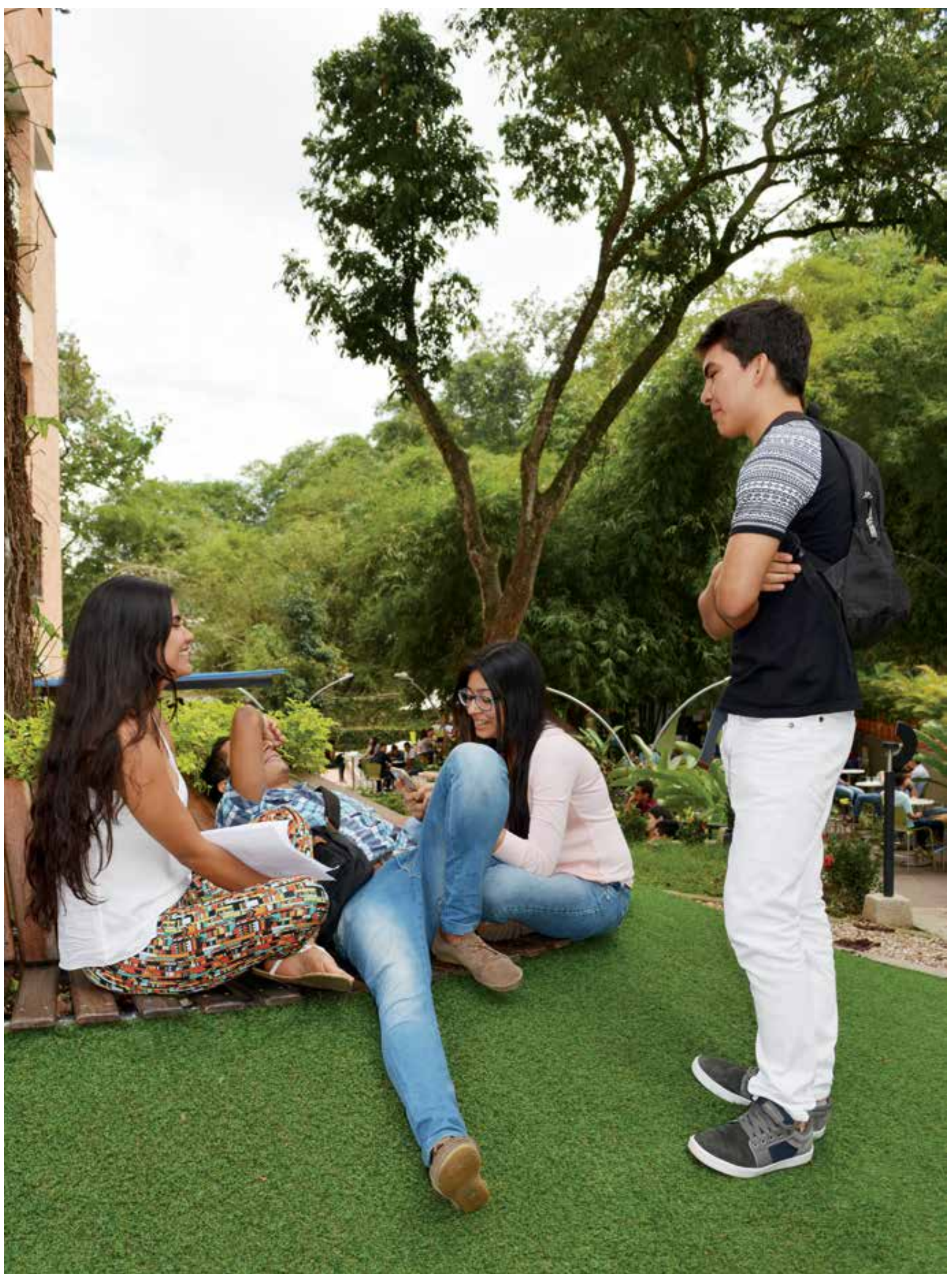


zar y clasificar, la lectura y el análisis de textos e imágenes (...)" (Perrenoud, 2004, p.109) Y estas competencias son susceptibles de desarrollar a través del libro que es un objeto comunicativo sui generis e irreemplazable.

La formación de sujetos de lenguaje a través de la lectura literaria en voz alta, convierte este acto en una poderosa herramienta de desarrollo social en comunidades vulnerables. Investigaciones como las del citado Jim Trelease en su Manual de Lectura en voz alta, ofrecen conclusiones que, a primera vista, parecen simplistas, pero están respaldadas por estudios que las convierte en universales y fehacientes y tienen más de acierto que de error:

1. Entre más lee uno, más sabe.

2. Entre más sabe uno, más inteligente es.

3. Entre más inteligente es uno, más tiempo puede permanecer en la escuela.

4. Entre más tiempo se escolarice uno, más diplomas obtiene y lo emplean por más tiempo, así gana más dinero.

5. Entre más diplomas obtenga, mejores notas obtendrán sus hijos en la escuela.

6. Entre más diplomas obtenga uno, más tiempo vivirá.

De acuerdo a las investigaciones arriba citadas, deberíamos darlo paso, entonces, al sentido común. Y éste nos dice que la lectura es una de las armas más poderosas que puede destruir la ignorancia, la pobreza y la falta de esperanza generada por la exclusión y la ausencia de oportunidades. Por esto, el proyecto Narración oral para niños y niñas del Asentamiento Humano Helechales: Hacia la inclusión social mediante la formación de sujetos de lenguaje es una apuesta a que la cultura del libro y de la lectura sea "la llave que abra las puertas del potencial creador de una comunidad o de una sociedad, la educación es la dimensión que puede confi- gurar y guiar el desarrollo de ese potencial" (De Zubiría, 2007, p. 28).

La mediación pedagógica y la consecuente dotación bibliográfica de la que gozarán treinta niños del Asentamiento Humano Helechales de Floridablanca, Santander, Colombia aspira a contribuir a la construcción de sujetos de lenguaje que con la apropiación del sentido crítico e imaginativo de la lectura de textos literarios serán capaces de leer el tiempo que les tocó vivir sin ser dominados por el discurso del demagogo, la artimaña del publicista, el énfasis del intolerante o cualquiera de tantas plagas que amarran a tantos en beneficio de unos pocos.

Así, la pregunta central que guiará este trabajo es la siguiente: ¿Cómo se modifican las competencias comunicativas y sociales de los niños y las niñas del Asentamiento Humano Helechales, a partir de su inmersión en un proceso de lectura literaria en voz alta? Pero la respuesta a ella, será objeto de un segundo artículo que se erigirá como un segundo avance de nuestra investigación.

\section{Conclusiones}

En esta primera etapa de diagnóstico del proyecto, es posible esbozar las siguientes conclusiones que nos harán avanzar en la realización del mismo:

La razón por la que concebimos el libro como nuestro conector o agenciador para la generación de sujetos del lenguaje se justifica en su carácter mediador de referentes y patrones socioculturales compartidos. El acto de compartir es muy representativo de la dimensión social, debido a que en su función de integración, significa hacer parte, involucrar, y entre partes que comparten es posible la participación.

El acto de leer tiene diversos sentidos, toma diferentes funciones una vez se realiza.

Por una parte el libro tiene una función integradora entre los niños y nosotros, borrando 


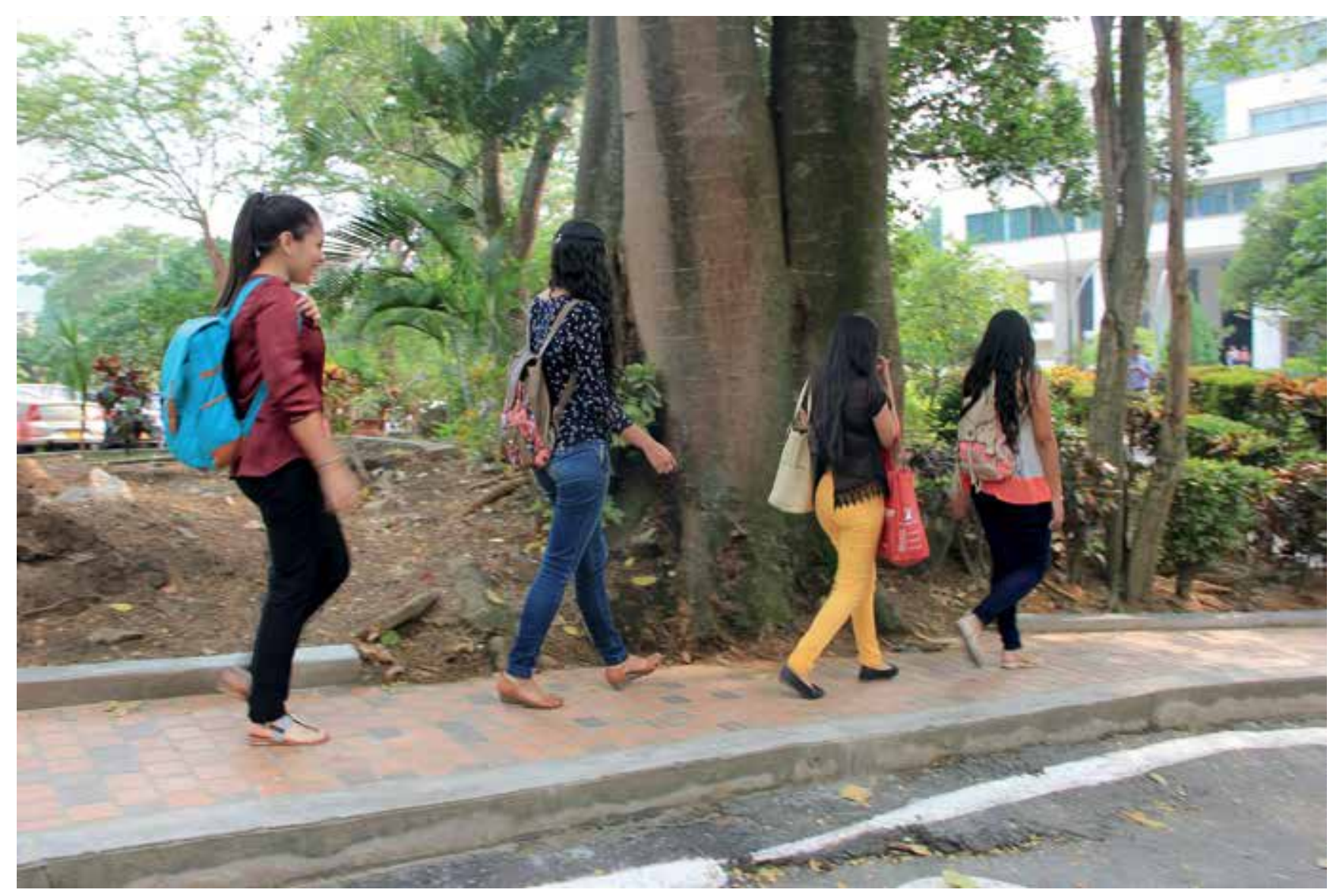

la concepción de actividades exclusivas, pues la lectura y el libro no conforman un monopolio. El libro nos permite la conexión y es razón de nuestro compartir, permitiéndonos un espacio de igualdad, reprimiendo las diferencias. Por otra parte nos permite que con cada lectura el niño trabaje con la historia para la construcción de su identidad y su ser como ciudadano, porque el libro abre un mundo conformado por ilustraciones, posibilidades y enseñanzas, permitiendo así, su participación en un contexto que inicialmente ajeno, lo irá incorporando en un proceso de transformación como ciudadano del mundo.

El modelo de educación liberal promueve la cultura del pluralismo, solidaridad, corresponsabilidad, aceptación de las diferencias, del dialogo y formación de ciudades. Es esta educación la que permite un desarrollo humano e integral a través de un proceso educativo que incluye el punto de vista ético, el compromiso con los derechos humanos y con la democracia participativa, donde no se habla de desarrollo, sin que haya un fomento de la libertad; porque sin educación no se puede pensar una sociedad. Cuando se comparte la educación a partir de la mediación intersubjetiva estamos en un plano de igualdad en el que las diferencias se convierten en el puente de comunicación que construye ciudadanía ya que reconocemos al otro y le damos participación.

Martha Nussbaum expone las habilidades que considera necesarias para el cultivo de la humanidad, las cuales son:

- Habilidad para un examen crítico.

- Capacidad de verse a sí mismo como seres vinculados a otros seres humanos por lazos de reconocimiento y de mutua preocupación.

- Capacidad de imaginación narrativa. 
Referente a esto Yolanda Reyes sostiene que por medio de la mediación pedagógica se sustenta la premisa que "la imaginación nos permite ser otros y ser nosotros mismos, descubrir que podemos pensarnos, nombrarnos, soñarnos, encontrarnos, conmovernos y descifrarnos" (Reyes, 2007 p. 13).

Con base en la caracterización de la población, se diseñará el plan de acción. Para ello se cuenta con los instrumentos de recolección de información sobre el nivel de competencias comunicativas y sociales de los niños y las niñas de Helechales. También se diseñará una guía de entrevista para maestros y padres de familia como instrumento para obtener información sobre los cambios que se puedan observar en las competencias comunicativas y sociales de los niños y las niñas.

Asimismo, se planificará la forma en que se realizará la mediación pedagógica a través del discurso literario. Se definirá el tipo y el número de actividades por realizar, como sesiones de narración oral, conversatorios, talleres, orientación a padres y madres y otras que puedan ser pertinentes, de acuerdo con las necesidades y la dinámica de los procesos que se desarrollen.

\section{Referencias}

Arroyave, E. (2008). La literatura en la educación inicial, un lineamiento curricular decisivo en la primera infancia. En Red Lecturas 6. Un espacio para la lectura y el diálogo razonado. Recuperado de [https://issuu.com/ nodoantioquia/docs/red_de_lecturas6_2_/87]

De Zubiría, J. (2011). Los modelos pedagógicos. Hacia una pedagogía dialogante. Bogotá: Cooperativa Editorial Magisterio.
Elliot, J. (1999). La investigación-acción en la educación. Barcelona: Morata.

Gisbert, J. M. (2007). La literatura, el misterio, la fantástica y los placeres del pensamientos. Cuaderno Sie7e. Revista literaria, 4. Concejalía de Cultura del Ayuntamiento de Coslada. Recuperado en diciembre 13 de 2015 de http://www.joanmanuelgisbert.com/wp-content/uploads/2010/12/cuadernosie7e_ok.pdf

Goyes, C. (2010). La narrativa: una perspectiva didáctica para orientar la educación en Derechos Humanos. En Educación en Derechos Humanos. Bogotá: Universidad del Valle.

Hernández, A. (s.f.). La desindustrialización en Colombia. Recuperado el 02 de marzo de 2016 de [http://www. zonaeconomica.com/colombia/desindustrializacion]

Montero, I., G. León, O. (2004). Sistema de clasificación del método en los informes de investigación. International Journal of Clinical and Health Psychology. Recuperado el 27 de enero de 2015 de [http://www.aepc. es/ijchp/articulos_pdf/ijchp-136.pdf]

Morin, E. (2000). La mente bien ordenada: Repensar la reforma. Reformar el pensamiento. Barcelona: Editorial Seix Barral. Los Tres Mundos.

Nussbaum, M. (2010). Recuperado el 23 de septiembre de 2015 de [http://institucional.us.es/revistas/themata/46/art_56.pdf .]

Perrenoud, P. (s.f.). Diez nuevas competencias para enseñar. Recuperado el 16 de febrero de 2016 de [https:// www.uv.mx/dgdaie/files/2013/09/Philippe-Perrenoud-Diez-nuevas-competencias-para-ensenar.pdf]

Reyes, Y. (2007). La casa imaginaria. Lectura y literatura en la primera infancia. Bogotá: Norma.

Sánchez de Serdio, A. (2010). Arte y educación: Diálogos y antagonismos. Revista Iberoamericana de Educación y Cultura, 52, 43-60.

Trelease, J. (2005). Manual de la lectura en voz alta. Bogotá: Fundalectura. 